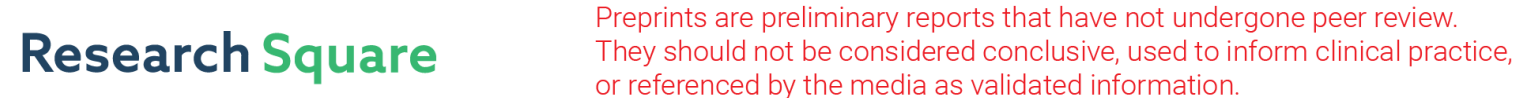 \\ Understanding public perceptions of nuclear energy in France
}

\section{Sandra Perez}

Christophe Den Auwer

Thierry Pourcher

Sandra Russo

Cyril Drouot

Maria Rosa Beccia

Gaelle Creff

Franck Fiorelli

Audrey Leriche

Fréderic Castagnola

Pascale Steichen

Geoges Carle

Hervé Michel

Nicolas Glaichenhaus

Denis Josse

Nicolas Pottier

Damienne Provitolo

\section{Video Byte}

Keywords: nuclear energy, radiation, radioactive material, clean energy, Université Côte d'Azur, nuclear power station, nuclear science, Energy Reports

Posted Date: November 12th, 2020

DOl: https://doi.org/10.21203/rs.3.rs-107417/v1

License: (1) This work is licensed under a Creative Commons Attribution 4.0 International License. Read Full License 


\section{Abstract}

Nuclear energy has historically been a source of fear among citizens, often due to the uncertainty associated with radioactive materials. Despite generating power with no carbon dioxide emissions, nuclear energy does not appear to be the public's frontrunner for replacing harmful fossil fuels, especially among young people. Would you change your mind about nuclear energy if you had more knowledge? "Non-expert" students from Université Côte d'Azur and an "expert" group of French firefighters with training in handling radiological and nuclear risks were surveyed about their perceptions and knowledge of nuclear energy. The two groups showed clear differences in perception, with students more likely to be scared of nuclear energy, and only slightly more than half of students considering French nuclear power stations to be safe. A majority of students did, however, indicate they were likely to change their minds about nuclear if provided more information. Overall, firefighters-who were more knowledgeable about nuclear science-appeared less in favor of an exit from nuclear energy. Understanding the public's perception of nuclear energy is a critical first step in shaping nuclear policy and in ensuring that people are aware of the true risks and benefits of nuclear energy. 